\section{Micropropagation of Lingonberry: Influence of Genotype, Explant Orientation, and Overcoming TDZ-induced Inhibition of Shoot Elongation Using Zeatin}

\author{
Samir C. Debnath ${ }^{1}$ \\ Atlantic Cool Climate Crop Research Centre, Agriculture and Agri-Food \\ Canada, St. John's, NL AlE 5Y7, Canada
}

Additional index words. micropropagation, Vaccinium vitis-idaea, cytokinin, ex vitro rooting

\begin{abstract}
In an attempt to improve the micropropagation protocol for lingonberry (Vaccinium vitis-idaea $\mathrm{L}$.) developed at the Centre, two lingonberry clones were compared for in vitro shoot proliferation on two different media supplemented with varying levels of thidiazuron (TDZ). TDZ supported proliferation at low concentrations (0.1 to $1 \mu \mathrm{M})$ but inhibited shoot elongation. However, usable shoots were obtained within 4 weeks by transferring shoot cluster to medium containing $1 \mu \mathrm{M}$ zeatin. Genotypes differed significantly with respect to multiplication rate with 'EL1' producing the most shoots per explant. In both genotypes, shoot proliferation was greatly influenced by explant orientation. Changing the orientation of explants from vertically upright to horizontal increased axillary shoot number, but decreased shoot height and leaf number per shoot. Proliferated shoots were rooted on a 2 peat : 1 perlite (v/v) medium, and the plantlets were acclimatized and eventually established in the greenhouse.
\end{abstract}

Lingonberry (Vaccinium vitis-idaea L.), an important fruit crop in many northern latitude countries (Gustavsson and Stanys, 2000; Jaakola et al., 2001), is a medicinal plant rich in anthocyanin (Stark et al., 1978) antioxidants (Wang et al., 1997). The Newfoundland lingonberry, also called partridgeberry, ranks first among Vaccinium species in terms of oxygen radical absorbance capacity (ORAC) containing higher antioxidants than lowbush blueberry, cranberry, and bilberry (W. Kalt, personal communication). The extract arbutin, derived from lingonberry leaves, is used for stomach disorders (Racz et al., 1962). This circumboreal woody, rhizomatous, evergreen dwarf shrub (Luby et al., 1991; Vander Kloet, 1988) can also be used as a landscape ornamental ground cover (Dierking and Dierking, 1993).

Two subspecies of $V$. vitis-idaea have been recognized. The larger lowland race as $V$. vitisidaea ssp. vitis-idaea (L.) Britton and the dwarf arctic-montane race as $V$. vitis-idaea ssp. minus (Lodd) Hult. (Hulten, 1949). The Canadian

Received for publication 21 Apr. 2004. Accepted for publication 12 July 2004. Atlantic Cool Climate Crop Research Centre contribution no. 165. The author gratefully acknowledges the cooperation of Boyd Penney who reviewed the manuscript internally. Appreciation is extended to Taimi Paal of the Forest Research Institute, Estonian Agricultural University, Tartu for providing the lingonberry clone, 'EL1'. Thanks are also due to Gary Bishop for internal manuscript review; and to Sarah Devine, Glen Chubbs, and Shawn Foley for their excellent technical help. I would like to acknowledge funding from the Canada Newfoundland Agricultural Safety Nets Initiative Program.

${ }^{1}$ Research scientist; e-mail debnaths@agr.gc.ca. province, Newfoundland and Labrador, is the largest North American lingonberry producing region (Penney et al., 1997) with about 140,000 $\mathrm{kg}$ harvested annually from native stands for processing, mostly for export (Jamieson, 2001). Other exporting countries are Sweden, Finland, and the former Soviet Union (Holloway, 1981; Liebster, 1977). Natural stands of lingonberries are harvested in Newfoundland, but due to the increased demand for the nutritious, natural fruit-based drinks, and other products that use processed lingonberries, demand now exceeds production. An increasing demand for berries of high quality has intensified the need to develop new cultivars for horticultural production. We initiated a program to develop improved lingonberry cultivars using biotechnology combined with classical breeding. Research on in vitro culture of the lingonberry which began at the Atlantic Cool Climate Crop Research Centre of Agriculture and Agri-Food Canada in St. John's, in 1999 under the Small
Fruit Development Program for Cool Climates has already yielded a considerable amount of information.

Thidiazuron, a substituted phenylurea ( $N$-phenyl- $N$ '-1,2,3-thidiazol-5-ylurea) with both cytokinin- and auxin-like effects (Mok et al., 1982; Visser et al., 1992), is a potent bioregulant of in vitro morphogenesis, and is now among the most active cytokinin-like substances for plant tissue culture. TDZ is used to induce shoot organogenesis in several species of recalcitrant woody plants (Murthy et al., 1998). The efficacy of TDZ for shoot proliferation has been demonstrated in apple (van Nieuwkerk et al., 1986), azaleas (Fellman et al., 1987), Quercus (Chalupa, 1988), carnation (Sankhla et al., 1995), Hevea (Seneviratne and Flagmann, 1996), cassava (Bhagwat et al., 1996), and rose (Singh and Syamal, 2001). While most of the early reports used the cytokinin $\mathrm{N}^{6}$-[2-isopentenyl]adenine (2iP) or zeatin for initiating new growth from lingonberry explants (Debnath and McRae, 2001a; Reed and Abdelnour-Esquivel, 1991; Serres et al., 1994), the effectiveness of TDZ on in vitro shoot proliferation has not been demonstrated with Vaccinium species. The objective of the current study was to determine the influence of TDZ in lingonberry for shoot proliferation and elongation testing of two native selections, one from Newfoundland and other from Estonia.

\section{Materials and Methods}

Plant material and establishment of shoot cultures. Young, actively growing lingonberry shoots of the Newfoundland clone, 'NL1' and the Estonian clone, 'EL1' were obtained from plants being maintained in a greenhouse. While 'EL1' belong to V. vitis-idaea ssp. vitis-idaea, the clone 'NL1' is in the group of $V$. vitis-idaea ssp. minus. Shoot-tip cultures, following the method of Debnath and McRae (2001a) were established in 175-mL glass baby-food jars containing $35 \mathrm{~mL} \mathrm{BM}$ medium [three-quarter macrosalts and microsalts of Debnath and McRae's (2001a) shoot proliferation medium D] supplemented with (per liter) 25 g sucrose, 3.5 g Sigma A 1296 agar, and 1.25 g Gelrite (Sigma Chemical Co., St. Louis). The medium $\mathrm{pH}$ was adjusted to 5.0 before autoclaving at $121^{\circ} \mathrm{C}$ for $20 \mathrm{~min}$. Zeatin $(5 \mu \mathrm{M})$ was filter-sterilized and added to autoclaved 
and cooled $\left(40\right.$ to $\left.50{ }^{\circ} \mathrm{C}\right) \mathrm{BM}$ medium. This medium worked well with 'NL1' and 'EL1'. Culture jars were capped with clear permeable polypropylene caps (Sigma Chemical Co., St. Louis). After explant transfer, jars were sealed with Parafilm, placed upright and maintained at $20 \pm 2{ }^{\circ} \mathrm{C}$ under a 16 -h photoperiod with a photosynthetic photon flux (PPF) density of $30 \mu \mathrm{mol} \cdot \mathrm{m}^{-2} \cdot \mathrm{s}^{-1}$ at the culture level provided by cool white fluorescent lamps.

Effect of TDZ concentration on shoot induction and proliferation from three-node explants. The purpose of this experiment was to determine the effect of TDZ concentration, explant orientation, medium salt formulation, and/or genotype influenced shoot induction and proliferation. A $2 \times 2 \times 4 \times 2$ factorial experiment (completely randomized) compared all combinations of two clones ('NL1' and 'EL1'), two media [BM and modified MS (Murashige and Skoog, 1962) medium containing half MS macrosalts and MS microsalts and vitamins (MMS)], four TDZ concentrations $(0,0.1,1$, and $5 \mu \mathrm{M}$ ), and two explant positions (vertical and horizontal). Three-node stem sections with leaves intact from in vitro shoots maintained for 8 weeks in BM without PGRs were cultured in 175-mL glass baby-food jars (Sigma Chemical Co., St. Louis) containing $35 \mathrm{~mL}$ media. There were four jars per treatment for each clone and each jar contained five explants. The experiment was conducted three times.

Shoot elongation, rooting, and acclimatization. Shoots of the clones 'NL1' and 'EL1' initiated on TDZ-containing medium were transferred to $175-\mathrm{mL}$ glass baby-food jars containing $35 \mathrm{~mL}$ BM supplemented with 1 $\mu \mathrm{M}$ zeatin after 8 weeks of culture initiation for elongation. Elongated shoots ( 3 to $4 \mathrm{~cm}$ long) were easily rooted using previously reported techniques (Debnath and McRae, 2001a). Briefly, shoots were excised just above the original explant, dipped in $39.4 \mathrm{~mm}$ indole3-butyric acid (IBA) powder (Stim-Root\#3, Plant Products Co. Ltd., Brampton, Ontario L6T 1G1, Canada) and planted in 45-cell plug trays $($ cell diameter $=5.9 \mathrm{~cm}$, cell depth $=15.1$ $\mathrm{cm}$; Beaver Plastics, Edmonton, Alberta T5V 1H5, Canada) containing 2 peat: 1 perlite (v/v). Trays were placed in a humidity chamber with a cool mist vaporizer at $22 \pm 2{ }^{\circ} \mathrm{C}, 95 \% \mathrm{RH}$ at $16 \mathrm{~h}$ photoperiod at $55 \mu \mathrm{mol} \cdot \mathrm{m}^{-2} \cdot \mathrm{s}^{-1} \mathrm{PPF}$ for rooting. Plantlets were transferred to $10.5(\mathrm{~L}) \times$ $10.5(\mathrm{~W}) \times 12.5(\mathrm{D}) \mathrm{cm}^{3}$ plastic pots containing the same medium as used for rooting, and acclimatized by gradually lowering the humidity over 2 to 3 weeks. Hardened-off plants were maintained in the greenhouse at $20 \pm 2{ }^{\circ} \mathrm{C}, 85 \%$ $\mathrm{RH}$, and 16-h photoperiod at a maximum PPF of $90 \mu \mathrm{mol} \cdot \mathrm{m}^{-2} \cdot \mathrm{s}^{-1}$. The number of surviving plants was recorded when they were removed from the humidity chamber (6 weeks).

Data collection and statistical analysis. The following growth characteristics of surviving explants were measured for each treatment at 8 weeks: number of shoots ( $>1 \mathrm{~cm}$ long) per responding explant, shoot length $(\mathrm{cm})$, number of leaves per shoot, shoot vigor, and callus size per explant. Vigor was determined by visual assessment (Fig. 1), on a scale of 1 (strongly vitrified, necrotic and/or malformed shoots) to 8 (fully normal and healthy shoots with excellent vigor); 2 = less vitrified, necrotic and/or malformed shoots; $3=$ no vitrification but with very poor vigor; $4=$ possessing poor shoot vigor; $5=$ with average shoot vigor; 6 $=$ having good shoot vigor; and $7=$ with very good shoot vigor. Callus size was rated as 0 (no callus formation) and $1(<2 \mathrm{~mm}$ in diameter) to 8 ( $>14 \mathrm{~mm}$ in diameter).

Data were subjected to analysis of variance with the SAS statistical software package (Release 8.2, SAS Institute, Inc., Cary, N.C.). The shoot number per explant was transformed to the square root scale, before the ANOVA to stabilize the variance. Statistical F tests were evaluated for shoot number, shoot height, and leaf number per shoot at $P \leq 0.05$. Shoot vigor and callus size were tested by using a categorical data modelling procedure (PROC CATMOD in SAS). This method is appropriate for the analysis of categorical data (Compton, 1994; Grizzle et al., 1969; Koch et al., 1982; Stanek et al., 1987), and allows assessment of both main effects and interaction terms (as in analysis of variance).

\section{Results and Discussion}

Effect of TDZ concentration on shoot induction and proliferation. All cuttings placed horizontally on the culture media responded by internal swelling and developed callus around the cut ends at 0 to $5 \mu \mathrm{M} \mathrm{TDZ}$ from day 6 to 8 of culture. Vertical placement induced callus formation at the basal end of the explants only. Axillary buds with multiple shoots developed at all TDZ concentrations.

Usually, calli were creamy white to pale brown in color, nodular and compact and sometimes exhibited patches of red pigmentation. TDZ concentration significantly $(P \leq 0.05)$ affected shoot proliferation and callus formation (Tables 1 and 2). Callus size increased with increasing dose of TDZ while shoot height, leaf number per shoot, and shoot vigor

Table 1. Effects of TDZ concentration and explant orientation on shoot number, shoot height, and leaf number per shoot for lingonberry clones, 'NL1' and 'EL1' grown in vitro on two culture mediaz.

\begin{tabular}{|c|c|c|c|}
\hline Treatment & $\begin{array}{c}\text { Shoots } \\
(\sqrt{ } \text { no./explant })\end{array}$ & $\begin{array}{l}\text { Shoot ht } \\
(\mathrm{cm})\end{array}$ & $\begin{array}{c}\text { Leaves } \\
\text { (no./shoot) }\end{array}$ \\
\hline \multicolumn{4}{|l|}{ Clone } \\
\hline 'NL1' & $1.4 \mathrm{~b}^{\mathrm{y}}$ & $2.2 \mathrm{~b}$ & $3.7 \mathrm{~b}$ \\
\hline 'EL1' & $1.5 \mathrm{a}$ & $3.0 \mathrm{a}$ & $4.5 \mathrm{a}$ \\
\hline \multicolumn{4}{|l|}{ Medium $^{\mathrm{x}}$} \\
\hline $\mathrm{BM}$ & $1.4 \mathrm{~b}$ & $2.7 \mathrm{a}$ & $4.4 \mathrm{a}$ \\
\hline MMS & $1.5 \mathrm{a}$ & $2.5 \mathrm{~b}$ & $3.8 \mathrm{~b}$ \\
\hline \multicolumn{4}{|c|}{ TDZ concentration $(\mu \mathrm{M})$} \\
\hline 0.0 & $1.0 \mathrm{~d}$ & $3.7 \mathrm{a}$ & $5.4 \mathrm{a}$ \\
\hline 0.1 & $1.6 \mathrm{~b}$ & $2.8 \mathrm{~b}$ & $4.8 \mathrm{~b}$ \\
\hline 1.0 & $1.8 \mathrm{a}$ & $2.4 \mathrm{c}$ & $3.7 \mathrm{c}$ \\
\hline 5.0 & $1.4 \mathrm{c}$ & $1.7 \mathrm{~d}$ & $2.6 \mathrm{~d}$ \\
\hline \multicolumn{4}{|l|}{ Explant orientation } \\
\hline Vertical & $1.4 \mathrm{~b}$ & $2.7 \mathrm{a}$ & $4.2 \mathrm{a}$ \\
\hline Horizontal & $1.5 \mathrm{a}$ & $2.5 \mathrm{~b}$ & $4.0 \mathrm{~b}$ \\
\hline \multirow[t]{4}{*}{ Significant effects ${ }^{\mathrm{w}}$} & $\mathrm{C}, \mathrm{M}, \mathrm{T}, \mathrm{E}$ & $\mathrm{C}, \mathrm{M}, \mathrm{T}, \mathrm{E}, \mathrm{C} \times \mathrm{M}$ & $\mathrm{C}, \mathrm{M}, \mathrm{T}, \mathrm{E}, \mathrm{C} \times \mathrm{T}$ \\
\hline & $\mathrm{C} \times \mathrm{T}, \mathrm{M} \times \mathrm{T}, \mathrm{T} \times \mathrm{E}$ & $\mathrm{C} \times \mathrm{T}, \mathrm{M} \times \mathrm{T}, \mathrm{C} \times \mathrm{M} \times \mathrm{E}$, & $\mathrm{M} \times \mathrm{T}, \mathrm{M} \times \mathrm{E}, \mathrm{T} \times \mathrm{E}$ \\
\hline & & $\mathrm{M} \times \mathrm{T} \times \mathrm{E}, \mathrm{C} \times \mathrm{M} \times \mathrm{T} \times \mathrm{E}$ & $\mathrm{C} \times \mathrm{M} \times \mathrm{T}, \mathrm{C} \times \mathrm{T} \times \mathrm{E}$ \\
\hline & & & $\mathrm{M} \times \mathrm{T} \times \mathrm{E}, \mathrm{C} \times \mathrm{M} \times \mathrm{T} \times \mathrm{E}$ \\
\hline
\end{tabular}

${ }^{2}$ Data were collected after 8 weeks in culture.

'Mean separation within columns and factors by Duncan's multiple range test, $P \leq 0.05$, whereby means associated with different letters signify significant differences.

xPlease see text for detail.

${ }^{\mathrm{w}}$ Significant effects $(P \leq 0.05): \mathrm{C}=$ clone, $\mathrm{M}=$ medium, $\mathrm{T}=\mathrm{TDZ}$ concentration, $\mathrm{E}=$ explant orientation 
Table 2. Effects of TDZ concentration and explant orientation on shoot vigor and callus size for lingonberry clones, 'NL1' and 'EL1' grown in vitro on two culture media'.

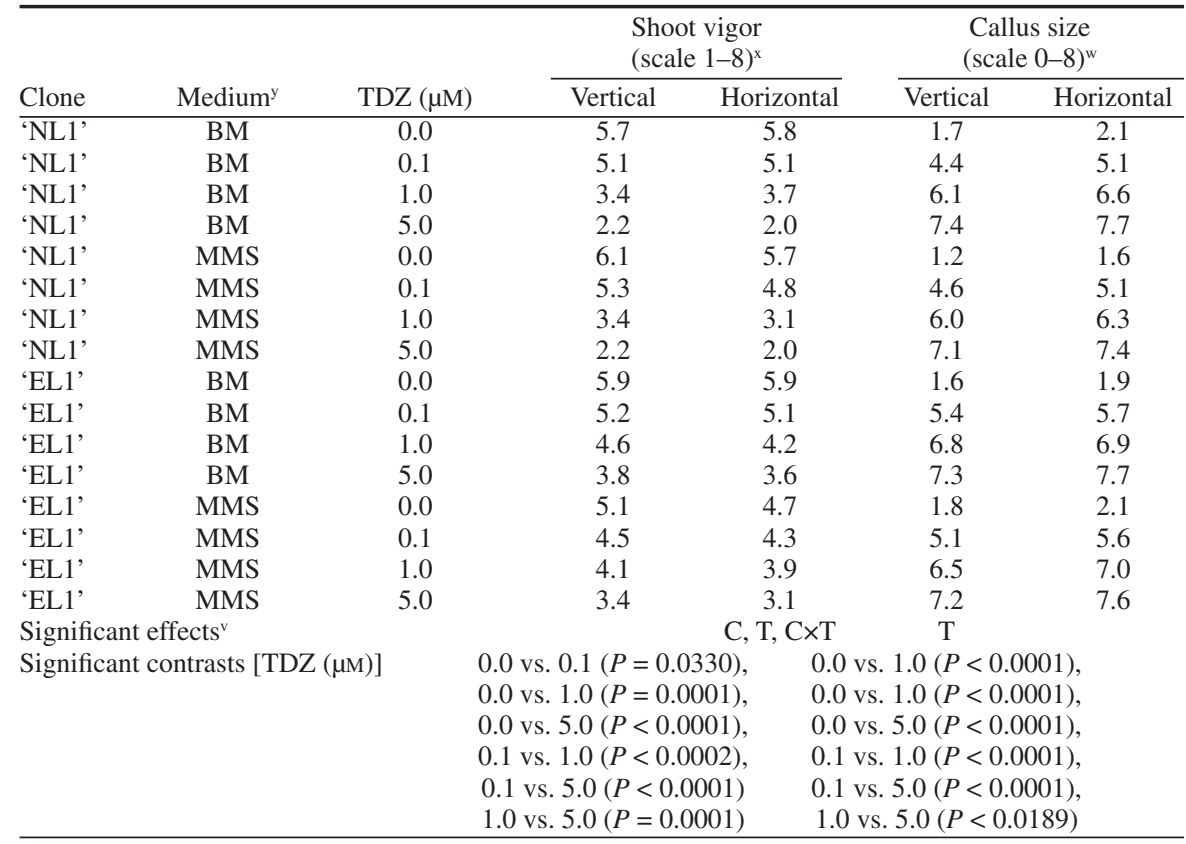

${ }^{2}$ Data were collected after 8 weeks in culture.

yPlease see text for detail.

${ }^{x}$ Shoot vigor was scored on a scale of 1 (strongly vitrified, necrotic and/or malformed shoots) to 8 (fully normal and healthy shoots with excellent vigor); $2=$ less vitrified, necrotic and/or malformed shoots; $3=$ no vitrification but with very poor vigor; $4=$ possessing poor shoot vigor; $5=$ with average shoot vigor; 6 $=$ having good shoot vigor; and 7 = with very good shoot vigor.

${ }^{\mathrm{w}}$ Callus size was rated as 0 (no callus formation) and 1 ( $<2 \mathrm{~mm}$ in diameter) to 8 ( $>14 \mathrm{~mm}$ in diameter). ${ }^{v}$ Significant effects $(P \leq 0.05)$ : $\mathrm{C}=$ clone, $\mathrm{T}=\mathrm{TDZ}$ concentration.

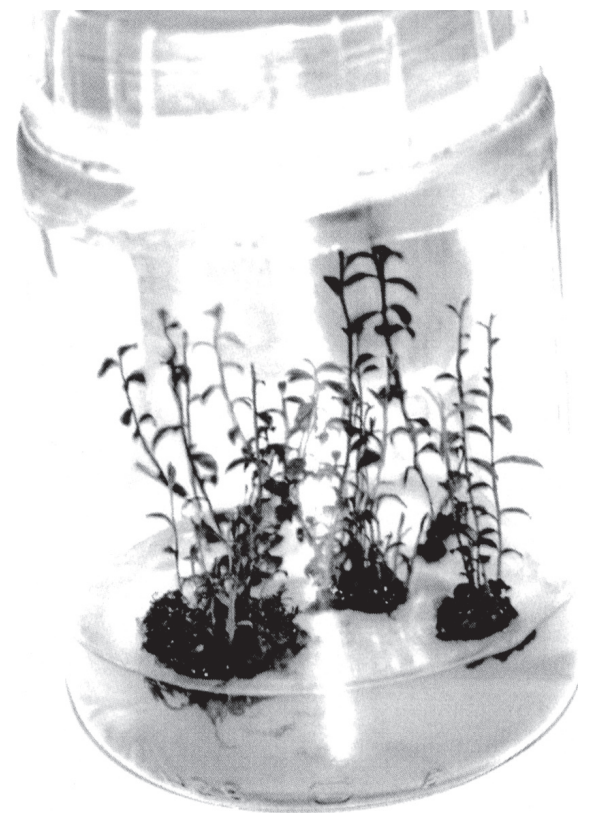

Fig. 2. Elongated shoots on $1 \mu \mathrm{M}$ zeatin-containing medium 4 weeks after transfer of 8-week-old thidiazuron $(1 \mu \mathrm{M})$-induced 'EL1' shoots from nodal explant.

in Table 1. The interactions among the four factors had major effects on shoot height and leaf number as they exhibited significant $\mathrm{F}$ values (Table 1).

Explants on cytokinin-free medium produced one unbranched shoot each, indicating strong apical dominance. Persistence of strong apical dominance is a major constraint in the development of efficient in vitro procedures for clonal propagation of some plant species (George and Sherrington, 1984). Indeed, axillary branching in nodal explants occurred only when TDZ was applied exogenously in the present study. TDZ has an apical dominance release that accelerates shoot proliferation observed in this study.

The clone often profoundly affects explant performance. Using shoot explants cultured on medium containing TDZ, Preece et al. (1991) and Kim et al. (1997) reported differences in axillary shoot proliferation among woody plant species. The clones in this study, which belong to two different subspecies, differed in their shoot multiplication and development potential (Tables 1 and 2). This result is reported in other studies on Vaccinium species including lingonberry (Debnath and McRae, 2001a; Serres et al., 1994) and cranberry (Debnath and McRae, 2001b; Marcotrigiano and McGlew, 1991; Smagula and Harker, 1997). Because cells within the same plant can have different endogenous levels of plant growth regulators and additional variation in receptor affinity or cellular sensitivity to plant growth regulators (Minocha, 1987), it is reasonable to expect that in vitro response will vary with clone. More studies on diverse genotypes, particularly within each subspecies, are required to further characterize genotypic variation of lingonberry responses to in vitro conditions.

In this study, clone 'EL1' exhibited better in vitro response than 'NL1' for axillary shoot proliferation (Tables 1 and 2). This trend continued with subsequent root formation and (Huetteman and Preece, 1993), which was plantlet establishment (data not shown). These results suggest that clone 'EL1' has further potential to serve as clonal plant material for in vitro studies of lingonberry.

In this study, shoots arising from node-associated callus in the medium at the explant base were termed 'short shoots' (basal shoots $<1 \mathrm{~cm}$ long) and were not counted as axillary shoots because it was difficult to distinguish whether short shoots were of axillary or adventitious origin. Nevertheless, short-shoot numbers appeared to increase with increasing TDZ concentration for both clones (data not shown). Adventitious bud formation in lingonberries was reported by Serres et al. (1994) for shoots grown on medium with high cytokinin concentrations. One objective of this study was to establish clonal material of specific genotypes. Axillary shoot material, which is easier to handle, was more useful than short shoots for subsequent rooting and plantlet establishment. Because adventitious shoots may have an increased frequency of somaclonal variation (Huetteman and Preece, 1993) and the clonal fidelity of short shoots is more questionable than that of axillary shoots, TDZ concentrations of $5 \mu \mathrm{M}$ or more should be avoided if nodal explants of lingonberries are to be cultured for clonal propagation. However, if the objective is to generate variability in a crop, a short callus step prior to adventitious shoot induction may prove effective.

Shoot elongation, rooting and acclimatization. Shoots of the clones 'NL1' and 'EL1' did not elongate $>2$ to $3 \mathrm{~cm}$ during the 8 weeks following culture initiation in $\mathrm{BM}$ containing 0.1 to $5 \mu \mathrm{M}$ TDZ. To encourage shoot elongation, cultures were then transferred to BM containing $1 \mu \mathrm{M}$ zeatin. Previous studies with adventitious shoots demonstrated that transferring clumps of adventitious shoots to BM with $1 \mu \mathrm{M}$ zeatin stimulated shoot development and elongation (Debnath, 2004). Applying a similar treatment to clumps of axillary shoots to medium containing $1 \mu \mathrm{M}$ zeatin improved shoot elongation within 4 weeks (Fig. 2).

The inhibition of shoot elongation by TDZ may be consistent with its high cytokinin activity (Huetteman and Preece, 1993). This has been reported in several fruit tree species including Malus (van Nieuwkerk et al., 1986) and Populus (Russel and McCown, 1986). In the present investigation, attempts to micropropagate shoots using the proliferation medium supplemented with TDZ were not successful due to excessive inhibition of shoot elongation. However, the TDZ effect could be overcome within 4 weeks by transferring TDZinitiated cultures to medium containing $1 \mu \mathrm{M}$ zeatin. Zeatin was also found to be effective for shoot initiation in Vaccinium species (Reed and Abdelnour-Esquivel, 1991), and for shoot proliferation of lingonberry (Debnath and McRae, 2001a) and highbush blueberry (Chandler and Draper, 1986; Eccher and Noe, 1989).

In vitro proliferated shoots for two clones rooted easily within 4 weeks, corroborating previous reports on lingonberry axillary shoots (Debnath and McRae, 2001a; Serres et al., 1994). Lingonberry microcuttings performed well in the greenhouse and plants acclimatized 
readily to the greenhouse with survival rates of $80 \%$ to $90 \%$.

Results achieved in this study demonstrate that 0.1 to $1 \mu \mathrm{M}$ TDZ can induce maximum shoot proliferation in lingonberry but must be eliminated for shoot elongation. Zeatin (1 $\mu \mathrm{M})$ must be used for shoot elongation before rooting. Compared to most other compounds with cytokinin activity, lower concentrations of TDZ can stimulate axillary shoot proliferation in many woody plants, whereas higher TDZ concentrations may result in the formation of both axillary and adventitious shoots (Chalupa, 1988; van Nieuwkerk et al., 1986). Shoot cultures of nodal explants became indistinguishable morphologically from the stock culture used as explant source, showing similar in vitro performance in terms of proliferation rate and rooting capacity.

\section{Literature Cited}

Bhagwat, B., L.G.E. Vieria, and L.R. Erickson. 1996. Stimulation of in vitro benzyladenine and gibberellic acid. Plant Cell Tiss. Organ Cult. 46:1-7.

Chalupa, V. 1988. Large scale micropropagation of Quercus sobur L. using adenine type cytokinins and thidiazuron to stimulate shoot proliferation. Biol. Plant 30:414-421.

Chandler, C.K. and A.D. Draper. 1986. Effect of zeatin and $2 \mathrm{iP}$ on shoot proliferation of three highbush blueberry clones in vitro. HortScience 21:1065-1066.

Compton, E.C. 1994. Statistical methods suitable for the analysis of plant tissue culture data. Plant Cell Tiss. Organ Cult. 37:217-242.

Debnath, S.C. 2004. A Two-step procedure for adventitious shoot regeneration from in vitroderived lingonberry leaves: Shoot induction with TDZ and shoot elongation using zeatin. HortScience 40(1):189-192.

Debnath, S.C. and K.B. McRae. 2001a. In vitro culture of lingonberry (Vaccinium vitis-idaea L.): The influence of cytokinins and media types on propagation. Small Fruits Rev. 1:3-19.

Debnath, S.C. and K.B. McRae. 2001b. An efficient in vitro shoot propagation of cranberry (Vaccinium macrocarpon Ait.) by axillary bud proliferation. In Vitro Cell. Dev. Biol. Plant 37:243-249.

Dierking, Jr., W. and S. Dierking, 1993. European Vaccinium species. Acta. Hort. 241:299-304.

Eccher, T. and N. Noe. 1989. Comparison between $2 \mathrm{iP}$ and zeatin in the micropropagation of highbush blueberry (Vaccinium corymbosum). Acta. Hort. 441:185-190.

Fellman, C.D., P.E. Read, and M.A. Hosier. 1987. Effects of thidiazuron and CPPU on meristem formation and shoot proliferation. HortScience 22:1197-1200.

George, E.F. and P.D. Sherrington. 1984. Plant propagation by tissue culture. Exegetics Ltd., Reading, U.K.
Grizzle, J.E., C.F. Starmer, and G.G. Koch. 1969. Analysis of categorical data by linear models. Biometrics 25:489-504.

Gustavsson, B.A. and V. Stanys. 2000. Field performance of 'Sanna' lingonberry derived by micropropagation vs. stem cuttings. HortScience 35:742-744.

Holloway, P.S. 1981. Studies on vegetative and reproductive growth of lingonberry ( $\mathrm{Vac}$ cinium vitis-idaea $\mathrm{L}$.). PhD diss. Univ. Minn., St. Paul.

Huetteman, C.A. and J.E. Preece. 1993. Thidiazuron: A potent cytokinin for woody plant tissue culture. Plant Cell Tiss. Org. Cult. 33:105-119.

Hulten, E. 1949. On the races in the Scandinavian flora. Svensk Botanisk Tidskrift Bd. 43:383-406

Jaakola, L., A. Tolvanen, K. Laine, and A. Hohtola. 2001. Effect of $\mathrm{N}^{6}$-isopentenyladenine concentration on growth initiation in vitro and rooting of bilberry and lingonberry microshoots. Plant Cell Tiss. Org. Cult. 66:73-77.

Jamieson, A.R. 2001. Horticulture in Canada-Spotlight on the Atlantic provinces. Chronica Hort. 42:8-11

Kim, M.K., H.E. Sommer, B.C. Bongarten, and S.A. Merkle. 1997. High-frequency induction of adventitious shoots from hypocotyls segments of Liquidambar styraciflua L. by thidiazuron. Plant Cell Rpt. 16:536-540.

Koch, G.G., I.A. Amara, G.W. Davis, and D.B Gillings. 1982. A review of some statistical methods for covariance analysis of categorical data. Biometrics 38:563-595.

Liebster, G. 1977. Experimental and research work on fruit species of the genus Vaccinium in Germany. Acta Hort. 61:19-24.

Luby J.J., J.R. Ballington, A.D. Draper, K. Pliszka, and M.E. Austin. 1991. Blueberries and cranberries (Vaccinium). Acta Hort. 290:391-456.

Marcotrigiano, M. and S.P. McGlew. 1991. A twostage micropropagation system for cranberries. J. Amer. Soc. Hort. Sci. 116:911-916.

Marks T.R. and S.E. Simpson. 1994. Factors affecting shoot development in apically dominant Acer cultivars in vitro. J. Hort. Sci. 69:543-551.

Minocha, S.C. 1987. Plant growth regulators and morphogenesis in cell and tissue culture of forest trees, p. 50-66. In: J.M. Bonga and D.J. Durzan (eds.). Cell and tissue culture in forestry. vol. 1. Martinus Nijhoff Publishers, Dordrecht, The Netherlands.

Mok, M.C., D.W.S. Mok, D.J.Armstrong, K. Shudo, Y. Isogai, and T. Okamoto. 1982. Cytokinin activity of $\mathrm{N}$-phenyl- $\mathrm{N}$-1,2,3-thiadizol-5-ylurea (thidiazuron). Phytochemistry 21:1509-1511.

Murashige, T. and F. Skoog. 1962. A revised medium for rapid growth and bioassays with tobacco tissue cultures. Physiol. Plant. 15:473-497.

Murthy, B.N.S., S.J. Murch, and P.K. Saxena. 1998. Thidiazuron: A potent regulator of in vitro plant morphogenesis. In Vitro Cell. Dev. Biol. Plant 34:267-275

Penney, B.G., P.A. Hendrickson, R.A. Churchill, and E. Butt. 1997. The wild partridgeberry (Vaccinium vitis-idaea L. var. minus Lodd) industry in Newfoundland and Labrador and the potential for expansion utilizing European cultivars. Acta Hort. 446:139-142.

Preece J.E., C.A. Huetteman, W.C. Ashby, and P.L. Roth. 1991. Micro and cutting propagation of silver maple. I. Results with adult and juvenile propagules. J. Amer. Soc. Hort. Sci. 116:142-148.

Racz, G., I. Fuzi, and L. Fulop. 1962. A method for determination of the arbutin content of cowberry leaves (Folium vitis-idaea). Rumanian Med. Rev. 6:88-90 (abstr.)

Reed, B.M. and A. Abdelnour-Esquivel. 1991. The use of zeatin to initiate in vitro cultures of Vaccinium species and cultivars. HortScience 26:1320-1322.

Russel J.A. and B.H. McCown. 1986. Thidiazuron stimulated shoot differentiation from protoplast derived calli of Populus, p. 49. In: Abstracts of 6th Intl. Cong. on Plant Tissue and Cell Cultures, Univ. Minn., Minneapolis.

Sankhla, D., T.D. Davis, N. Sankhla, and A. Upadhyaya. 1995. In vitro regeneration of heat tolerant 'German Red' carnation through organogenesis and somatic embryogenesis. Gartenbauwissenschaft 60:228-232.

Seneviratne, P. and A. Flagmann. 1996. The effect of thididazuron on axillary shoot proliferation of Hevea brasiliensis in vitro. J. Rubber Res. Inst., Sri Lanka 77:1-14.

Serres, R.A., S. Pan, B.H. McCown, and E.J. Stang. 1994. Micropropagation of several lingonberry cultivars. Fruit Var. J. 48:7-14.

Singh S.K. and M.M. Syamal. 2001. A short preculture soak in thidiazuron or forchlorfenuron improves axillary shoot proliferation in rose micropropagation. Sci. Hort. 91:169-177.

Smagula, J.M. and J. Harker. 1997. Cranberry micropropagation using a lowbush blueberry medium. Acta Hort. 446:343-347.

Stanek III, E.J., S.R. Diehl, M. Dgetluck, M.E. Stokes, and R.J. Prokopy. 1987. Statistical methods for analyzing discrete responses of insects tested repeatedly. Environ. Entomol. 16:319-326.

Stark, R., I.V. Hall, and P.A. Hendrickson. 1978 The partridgeberry of Newfoundland. Canadex (Hort. Crops) 230.

Tao, W. and J. Verbelen. 1996. Switching on and off cell division in cultured mesophyll protoplasts of tobacco. Plant Sci. 116:107-115.

van Nieuwkerk, J.P., R.H. Zimmerman, and I. Fordham. 1986. Thidiazuron stimulation of apple shoot proliferation in vitro. HortScience 21:516-518.

Vander Kloet, S.P. 1988. The genus Vaccinium in North America. Agr. Can. Publ. 1828.

Visser, C., J.A. Qureshi, R. Gill, and P.K. Saxena. 1992. Morphoregulatory role of thidiazuron: Substitution of auxin and cytokinin requirement for the induction of somatic embryogenesis in geranium hypocotyl cultures. Plant Physiol. 99:1704-1707.

Wang, H., G. Cao, and R.L. Prior. 1997. Oxygen radical absorbing capacity of anthocyanins. J. Agr. Food Chem. 45:304-309. 